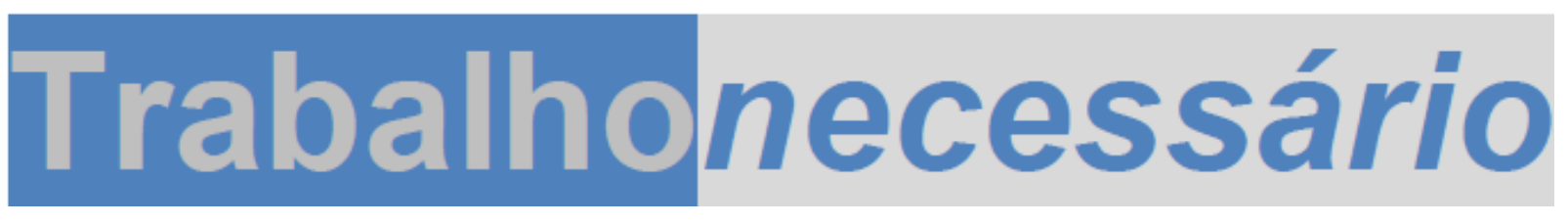

Issn: 1808 - 799X

ano 11, no $16-2013$

\title{
FORMAÇÃO HUMANA NO INSTUTITO POLITÉCNICO DA UFRJ: O TRABALHO COMO PRINCÍPIO EDUCATIVO A PARTIR DA PEDAGOGIA DE PROJETOS
}

\author{
Vitor Bemvindo ${ }^{1}$ \\ Cosme Almeida ${ }^{2}$ \\ Jullia Turrini ${ }^{3}$
}

\begin{abstract}
Resumo: O presente artigo pretende analisar a concepção de formação humana do Instituto Politécnico da Universidade Federal do Rio de Janeiro (IPUFRJ), em Cabo Frio, a partir da questão do trabalho como princípio educativo. Fundado em 2008, o IPUFRJ apresenta uma proposta de formação profissional integrada ao Ensino Médio, de base contra-hegemônica, tendo a politecnia como referência. Ao longo desses anos, o Instituto vem desenvolvendo uma alternativa metodológica de ensino, calcada na Pedagogia de Projetos, que tem se mostrado uma inovadora experiência na abordagem da educação pelo trabalho. No entanto, tal experiência ainda carece de estudos mais aprofundados. Nesse contexto, este trabalho pretende analisar as contribuições do IPUFRJ, tendo como base 0 estudo de um dos projetos pedagógicos da escola, posto em prática em 2011, com os alunos do segundo ano do curso técnico integrado ao Ensino Médio de Cultura Marítima. Tal projeto teve como objetivo introduzir técnicas de construção naval a partir da construção de uma prancha de surfe feita de agave. Neste sentido, busca-se aqui estabelecer possíveis relações entre o que fora formulado por pensadores como Marx e Gramsci e a experiência do IPUFRJ, tendo em vista possíveis contribuições para o desenvolvimento de uma educação que proporcione uma formação humana plena.
\end{abstract}

\footnotetext{
${ }^{1}$ Doutorando em Educação pela UFF, mestre em História pela UERJ, bacharel e licenciado em História pela UFF. Atua como professor-bolsista do Instituto Politécnico da UFRJ em Cabo Frio, desde 2010.

${ }^{2}$ Mestrando em Educação pela UNIRIO. Licenciado em História pela UVA. Atuou como professorbolsista do IPUFRJ entre 2008 e 2011.

${ }^{3}$ Licenciada em Ciências Sociais pela UFJF. Atua como professora-bolsista do IPUFRJ, desde 2011.
}

TrabalhoNecessário - www.uff.br/trabalhonecessario; Ano 11, № 16/2013. 


\title{
Trabalhonecessário
}

Issn: 1808 - 799X

ano 11, no $16-2013$

Palavras-chave: Trabalho como princípio educativo; politecnia; formação humana

\begin{abstract}
This article aims to analyse the conception of human formation of the Instituto Politécnico da Universidade Federal do Rio de Janeiro (IPUFRJ), in Cabo Frio, from the issue of labor as an educational principle. Founded in 2008, the IPUFRJ presents a proposal for integrated professional training school and high school, based in counter-hegemonic ideas, taking as reference the polytechnic. Throughout these years, the Institute has developed an alternative teaching methodology, based on Project Method, which has proven an innovative experience in approach to education through labor. However, this experience still needs further study. In this context, this study aims to examine the contributions of IPUFRJ, based on the study of one of the school's educational projects, implemented in 2011, with students of the second year of the integrated technical course of Marine Culture. This project aimed to introduce techniques of shipbuilding from the construction of a surfboard made of agave. In this sense, we seek to establish possible links between what had been formulated by thinkers such as Marx and Gramsci and experience IPUFRJ, in view of possible contributions to the development of an education that provides a full human formation.
\end{abstract}

Keywords: Labor as an educational principle, Polytechnic, Human formation. 


\section{Trabalhonecessário}

Issn: 1808 - 799X

ano 11, no $16-2013$

\section{Apresentação}

Nas últimas três décadas, houve intensos debates acerca da formação profissional de nível médio no Brasil. A partir dos anos de 1990, quando das discussões em torno da Lei de Diretrizes e Bases da Educação (LDB), é possível notar grande produção acadêmica sobre o tema, o que evidencia, na verdade, a oposição entre duas concepções antagônicas de formação profissional, a primeira delas alicerçada no que Frigotto (2001) chamou de educação profissional gerida pelos "homens de negócio", com base nas necessidades do mercado e no controle autoritário dos meios de produção. Em contraposição a essa ideia, está a concepção de ensino médio integrado à educação profissional de base unitária que pressupõe a indissociação entre o trabalho manual e intelectual - e que aponte caminhos para uma educação omnilateral e politécnica.

As políticas educacionais, nos anos do governo Fernando Henrique Cardoso acompanharam uma tendência global de regulação curricular, culminando na aprovação da LDB, em 1996 e do Decreto n. 2208/97. Este movimento de reformas na educação brasileira explicitava a política para a educação profissional que seria implantada a partir da década de 1990. A regulamentação deste decreto, determinava que a educação profissional teria organização curricular própria e independente, havendo a articulação apenas de forma concomitante ou sequencial ao ensino médio. Nesse momento a dualidade entre a educação profissional e a educação geral se tornou mais evidente através de um modelo tecnicista, aprofundando a dicotomia entre teoria e prática.

Já na primeira década do século XXI, durante o governo Lula da Silva, a revogação do Decreto 2208/97 e a aprovação do Decreto 5154/04, sinalizou a retomada das discussões em torno da formação profissional. Entretanto, percebese que em relação ao primeiro houve apenas uma distinção mais clara quanto as

TrabalhoNecessário - www.uff.br/trabalhonecessario; Ano 11, № 16/2013. 


\title{
Trabalhonecessário
}

Issn: 1808 - 799X

ano $11, \mathrm{n}=16-2013$

modalidades de ensino profissional. O novo decreto representou de forma tímida a possibilidade de uma organização da educação profissional de forma integrada, isto é, com uma só matriz curricular.

Todavia, a abertura dada a perspectiva de formação integrada do ensino médio a educação profissional ainda não recuperava as questões relativas à concepção de educação politécnica, de educação omnilateral e de escola unitária. Limitando o decreto a inclusão de uma modalidade de ensino, que possibilitasse a articulação entre o ensino médio e o profissional de modo simultâneo, sem de fato discutir conceitualmente de que tipo de integração se esperava construir.

Mais recentemente, nos primeiros anos da presente década, a defesa da concepção de formação profissional integrada ao ensino médio ganhou novo fôlego, com as discussões relacionadas às Diretrizes Curriculares Nacionais para a Educação Profissional Técnica de Nível Médio. O documento aprovado pela Câmara de Educação Básica, no dia 9 de maio de 2012, sugere a definição a seguir para a formação integrada:

\begin{abstract}
Assim, quando se fala em formação integrada ou no Ensino Médio integrado à Educação Profissional Técnica de Nível Médio, em quaisquer das suas formas de oferta, o que se quer dizer com essa concepção, é que a formação geral do aluno deve se tornar inseparável da formação profissional e vice-versa, em todos os campos onde se dá essa preparação para o trabalho: seja nos processos produtivos, seja nos processos educativos, tais como o Ensino Fundamental e o Ensino Médio, seja na formação inicial ou qualificação profissional, seja na Educação Profissional Técnica e ou na Tecnológica, bem como nos demais cursos superiores. Significa enfocar o trabalho como princípio educativo, objetivando superar a tradicional e preconceituosa dicotomia entre trabalho manual e trabalho intelectual, incorporando a dimensão intelectual ao trabalho produtivo e viceversa, objetivando a formação de trabalhadores capazes de atuar democraticamente como cidadãos, na posição de dirigentes ou de subordinados. Para tanto, como está definido no inciso IV do art. 35 da LDB, é preciso propiciar aos alunos a "compreensão dos fundamentos científico-tecnológicos dos processos produtivos, relacionando a teoria com a prática, no ensino de cada disciplina" (CONSELHO, 2012, p. 29).
\end{abstract}

Nessa perspectiva, surge uma série de grandes desafios no que concerne à aplicação prática desses princípios na construção de uma modalidade de ensino

TrabalhoNecessário - www.uff.br/trabalhonecessario; Ano 11, № 16/2013. 


\section{Trabalhonecessário}

Issn: 1808 - 799X

ano 11, no $16-2013$

profissional que ofereça aos trabalhadores uma educação integral. O primeiro desses desafios está ligado à disseminação dessa concepção de educação profissional, que ainda disputará espaço com as modalidades concomitante e subsequente. Além disso, num contexto de ampliação de investimentos na educação profissional, prenunciado pelo Programa Nacional de Acesso ao Ensino Técnico e Emprego (Pronatec), é importante lutar para que a formação integrada seja prioritária no recebimento de recursos e de apoio administrativo para que as conquistas não se tornem meras instruções burocráticas.

Além disso, entre esses desafios está a estruturação de uma prática pedagógica fundamentada na formação integrada. É importante ressaltar que são raras e esparsas as experiências que realmente tenham levado em consideração a integração efetiva das formações geral e profissional, sendo necessário, portanto, construir-se um referencial para que o ensino médio integrado se desenvolva.

Nesse contexto, as iniciativas que se utilizem dessa modalidade de formação profissional precisam ser estudadas e analisadas com detalhamento, visando construir novos horizontes para a formação de trabalhadores no Brasil. Uma dessas inciativas, que será foco de análise neste artigo, é a do Instituto Politécnico da Universidade Federal do Rio de Janeiro em Cabo Frio (IPUFRJ). Fundado em 2008, o IPUFRJ apresenta uma proposta de formação profissional integrada ao Ensino Médio, tendo a politecnia como referência. Ao longo desses anos, o Instituto vem desenvolvendo uma alternativa metodológica de ensino calcada na Pedagogia de Projetos, que tem se mostrado uma inovadora experiência na abordagem da educação pelo trabalho.

Por isso, acredita-se que, a partir da compreensão da concepção de formação humana do Instituto Politécnico, pode-se identificar contribuições importantes para a consolidação da forma integrada de formação profissional.

TrabalhoNecessário - www.uff.br/trabalhonecessario; Ano 11, № 16/2013. 


\section{Trabalhonecessário}

Issn: 1808 - 799X

ano 11, no $16-2013$

Essas contribuições estão, principalmente, no campo da metodologia de ensino, dado o caráter inovador da abordagem do trabalho como princípio educativo, articulado à Pedagogia de Projetos.

Portanto, pretende-se analisar a experiência do IPUFRJ, a partir do estudo de um dos projetos pedagógicos desenvolvidos na escola, com o intuito de indicar possíveis contribuições para aplicação da formação profissional de base unitária. Para isso, iniciamos com a caracterização dos referenciais teóricos relacionados ao trabalho como princípio educativo, a partir da concepção de Karl Marx e de Antonio Gramsci. Além disso, será feita uma caracterização do Instituto Politécnico da UFRJ, enfocando suas referências, metodologia de ensino e proposta político-pedagógica. Por fim, o trabalho se deterá mais minuciosamente no estudo de um dos projetos pedagógicos desenvolvidos na escola, com o intuito de compreender como o trabalho atua como princípio educativo, a partir da Pedagogia de Projetos, dentro o IPUFRJ.

\section{Trabalho como princípio educativo: o referencial teórico}

As maiores contribuições para o debate teórico em torno da relação entre trabalho e educação vem do pensamento marxista. $O$ curioso é que nem Karl Marx, nem Friedrich Engels dedicaram um estudo exclusivo às questões relacionadas ao trabalho e à educação. Assim sendo, os elementos que se tem a respeito do tema resultam de um olhar mais atento à leitura de suas obras nas quais o aspecto educacional, ou precisamente a formação humana, aparece como elemento integrante de uma teoria mais complexa sobre o funcionamento da sociedade capitalista. Dessa forma, percebe-se que a formação humana em Marx está atrelada a uma pretensão maior, que seria a superação dessa mesma sociedade.

TrabalhoNecessário - www.uff.br/trabalhonecessario; Ano 11, № 16/2013. 


\title{
Trabalhonecessário
}

Issn: 1808 - 799X

ano 11, no $16-2013$

Marx define três dimensões importantes a serem desenvolvidos pelo educando no processo formativo, a saber: educação corporal, educação intelectual e educação tecnológica, ou seja, a proposta de formação humana passa pelo desenvolvimento destes aspectos. Porém, a realização deste processo não pode ocorrer de forma fragmentada; ao contrário, obrigatoriamente deve acontecer de maneira articulada. Neste sentido, a categoria trabalho assume papel preponderante no processo educativo em Marx. As palavras de Manacorda (2010a) nos ajudam a compreender com mais clareza a importância destes três aspectos e sua relação com a categoria trabalho:

\begin{abstract}
Sua concepção de instrução é delineada numa forma explícita e detalhada nas instruções aos delegados ao I Congresso da Internacional dos Trabalhadores, que se realizou em Genebra em setembro de 1866; aqui, após ter aceito, sem sentimentalismos, a tendência da indústria a introduzir na produção a colaboração de crianças e adolescentes de ambos os sexos, desde que isso aconteça de modo adequado às forças infantis, e após ter afirmado que, cada um deve participar do trabalho produtivo e trabalhar não somente com o cérebro mas também com as mãos, ele assim precisa sua concepção: "por instrução nós entendemos três coisas: instrução intelectual, (...) educação física, assim como é ministrada nas escolas de ginástica e pelos exércitos militares, (...) treinamento tecnológico, que transmita os fundamentos científicos gerais de todos os processos de produção e que contemporaneamente introduza a criança e o adolescente no uso prático e na capacidade de manusear os instrumentos elementares de todos os ofícios". (MANACORDA, 2010a, p. 358)
\end{abstract}

A partir do exposto, percebe-se que Marx tinha uma preocupação com a formação plena da classe trabalhadora, mais precisamente com as condições em que viviam na sociedade e sua potencialidade para transformar a realidade. Desenvolver os três aspectos significava preparar os trabalhadores para enfrentar os principais desafios postos pela sociedade capitalista. Porém, este processo deveria articular atividades motoras e intelectuais relacionadas diretamente com a realidade concreta, isto é, com situações reais do processo produtivo. Dessa forma, o trabalho ganha contornos especiais pela sua natureza essencialmente humana e pelo seu caráter histórico:

TrabalhoNecessário - www.uff.br/trabalhonecessario; Ano 11, № 16/2013. 


\title{
Trabalhonecessário
}

Issn: 1808 - 799X

ano $11, \mathrm{n}=16-2013$

\begin{abstract}
Mais do que tudo, ele tem em mente uma unidade diversa entre instrução e trabalho, para todos: a presença das crianças contemporaneamente nas estruturas escolásticas e nas estruturas produtivas e uma instrução tecnológica que, longe de orientar uns para uma profissão e outros para outra, sirva para dar a todos, indistintamente, tanto um conhecimento da totalidade das ciências, como as capacidades práticas em todas as atividades produtivas. Ela visava, enfim, a uma formação de homens total e onilateralmente desenvolvidos. (MANACORDA, 2010a, p. 359)
\end{abstract}

Para Marx, a formação humana deve ter o trabalho como elemento central. O trabalho é necessariamente o princípio educativo, pois o homem historicamente tem produzido a sua existência através do mesmo, sendo esta, então, a principal atividade humana. Porém, não se trata de qualquer trabalho, mas o mesmo entendido como meio pelo qual o homem transforma a natureza e a si mesmo diferenciando-se assim, dos outros animais. Neste processo, o homem se humaniza por meio do trabalho, agindo sobre a realidade objetiva, humanizando 0 mundo:

Portanto, o que diferencia o homem dos outros animais é o trabalho. E o trabalho instaurase a partir do momento em que seu agente antecipa mentalmente a finalidade da ação. Consequentemente, não é qualquer tipo de atividade, mas uma ação adequada a finalidades. É, pois, uma ação intencional. (SAVIANI, 2003, p.11).

Por isso, o trabalho emerge como categoria fundamental no processo formativo no pensamento marxista, pois a sociedade capitalista agravou o fosso entre o trabalho manual e intelectual, relegando o primeiro às classes subalternas e gerando um estado de alienação. Superar a sociedade capitalista passa por uma formação que resgate a unicidade entre o trabalho manual e intelectual, ou seja, apresenta como desafio o rompimento com a fragmentação do conhecimento, promovendo assim, a apropriação dos conceitos a partir da relação constante entre teoria e prática no contexto do trabalho produtivo. Este 


\section{Trabalhonecessário}

Issn: 1808 - 799X

ano $11, \mathrm{n}=16-2013$

movimento possibilitaria uma educação integral, o desenvolvimento pleno, omnilateral do homem:

Frente à realidade da alienação humana, na qual todo homem, alienado por outro, está alienado da própria natureza, e o desenvolvimento positivo está alienado a uma esfera restrita, está a exigência da onilateralidade, de um desenvolvimento total, completo, multilateral, em todos os sentidos, das faculdades e das forças produtivas, das necessidades e da capacidade de sua satisfação. (...) Estabelece-se, então, um nexo recíproco pelo qual o indivíduo não pode desenvolver-se onilareralmente se não há uma totalidade de forças produtivas, e uma totalidade de forças produtivas não pode ser dominada a não ser pela totalidade dos indivíduos livremente associados. (MANACORDA, 2010a, p. 94)

Outro aspecto relevante trata-se do método do materialismo histórico e dialético e a práxis educativa. Entender as mudanças da sociedade como um movimento histórico determinado pelas relações sociais em cada temporalidade e pelas contradições dos diversos grupos que as compõem permite romper com uma visão idealista de mundo. Desenvolver uma proposta de formação humana para a transformação social passa pela apropriação deste método pelos educadores e pelos educandos, pois possibilita a superação de uma visão impregnada pela ideologia dominante, permitindo a tomada de consciência da realidade concreta e contribuindo para intervir de forma ativa e crítica na sociedade:

$\mathrm{Na}$ perspectiva materialista histórica, o método está vinculado a uma concepção de realidade, de mundo e de vida no seu conjunto. A questão da postura, neste sentido, antecede ao método. Este constitui-se numa espécie de mediação no processo de apreender, revelar e expor a estruturação, o desenvolvimento e transformação dos fenômenos sociais. (...) Romper com o modo de pensar dominante ou com a ideologia dominante é, pois, condição necessária para instaurar um método dialético de investigação. (FRIGOTTO, 2004, p. 77)

Outra importante contribuição para se pensar a formação humana numa perspectiva emancipatória deriva das obras de Antônio Gramsci. Este autor

TrabalhoNecessário - www.uff.br/trabalhonecessario; Ano 11, № 16/2013. 


\title{
Trabalhonecessário
}

Issn: 1808 - 799X

ano $11, \mathrm{n}=16-2013$

entende que a escola funciona, historicamente, como um aparelho de hegemonia. No entanto, ele crê que o espaço educacional também pode servir a uma formação humana que se imponha, de forma antagônica, à ideologia dominante. Isso quer dizer que a escola pode ser um espaço contra-hegemônico de organização e reflexão, ao invés de ser apenas um espaço de adequação das ideologias hegemônicas.

Assim sendo, a proposta de formação humana em Gramsci fundamenta-se a partir de três pressupostos básicos: escola desinteressada, escola unitária e trabalho industrial. Vivendo num contexto no qual o trabalho industrial já havia atingido um estágio muito avançado em seu processo de desenvolvimento, o autor denuncia o problema da escola que forma para atender os interesses imediatos, ou seja, uma escola imediatista. As crianças, desde cedo, seriam condicionadas a desenvolver determinadas aptidões com o intuito de ocupar posição previamente estabelecida. Os filhos da burguesia assumindo postos de comando no processo produtivo - trabalho intelectual -, e os filhos de operários ocupando funções subalternas - trabalho manual. Neste sentido, a escola servia à reprodução das desigualdades marcadamente presentes na sociedade capitalista.

\begin{abstract}
A tendência atual é a de abolir qualquer tipo de escola 'desinteressada' (não imediatamente interessada) e 'formativa', ou de conservar apenas um seu reduzido exemplar, destinado a uma pequena elite de senhores e de mulheres que não devem pensar em preparar-se para um futuro profissional, bem como a de difundir cada vez mais as escolas profissionais especializadas, nas quais o destino do aluno e sua futura atividade são predeterminados. (GRAMSCI, p.33, 2004)
\end{abstract}

Contrário à perspectiva de escola voltada, apenas a profissionalização, Gramsci defende um modelo escolar que privilegie a formação para a prática social, relegando a formação específica para um momento de maior maturação da personalidade do educando, quando teria mais autonomia para escolher a 


\section{Trabalhonecessário}

Issn: 1808 - 799X

ano $11, \mathrm{n}=16-2013$

carreira profissional. Neste sentido, a preocupação com a atividade social deve anteceder a atividade produtiva quando se pensa em formação humana.

Dessa forma, ele propõe uma escola desinteressada, ou seja, uma escola que não fosse simplesmente para atender os interesses imediatos do processo produtivo. A escola desinteressada se caracteriza pelo empenho em promover uma educação integral - aqui entendida a partir do conceito marxiano, uma formação omnilateral. Neste sentido, acredita que uma escola para desenvolver tal aspecto precisaria romper com a estrutura de escola vigente naquela sociedade - e na nossa também. Isso significa uma nova proposta de escola quanto a sua estrutura, funcionamento e, sobretudo a concepção político-filosófica que orienta o trabalho educativo ${ }^{4}$. Significa mudar a concepção pedagógica, tendo em vista uma formação coletiva.

A partir dessa perspectiva, Gramsci propõe a "escola unitária". Não cabe aqui, devido ao reduzido espaço, fazer uma longa caracterização desta proposição. Limitamo-nos, portanto, a enunciar os princípios básicos da escola unitária, que se baseia na unidade entre a instrução e o trabalho, ou seja, na associação entre os trabalhos intelectual e manual. Além disso, a escola proposta pelo autor preconiza a formação de trabalhadores que sejam capazes de se tornarem dirigentes, alcançando assim, a compreensão totalizante do processo produtivo, através dos conhecimentos referentes às "leis da natureza, das humanidades e da ordem legal que regula a vida em sociedade" (CIAVATTA, 2008, p. 412).

\footnotetext{
${ }^{4}$ Usamos o termo a partir da concepção de Saviani: "o trabalho educativo é o ato de produzir, direta e intencionalmente, em cada indivíduo singular, a humanidade que é produzida histórica e coletivamente pelo conjunto dos homens. Assim, o objeto da educação diz respeito, de um lado, a identificação dos elementos culturais que precisam ser assimilados pelos indivíduos da espécie humana para que eles se tornem humanos e, de outro lado e concomitantemente, à descoberta das formas mais adequadas para atingir esse objetivo". (SAVIANI, p. 13, 2008).
} 


\section{Trabalhonecessário}

Issn: 1808 - 799X

ano $11, \mathrm{n}=16-2013$

\section{Instituto Politécnico da UFRJ: uma escola em construção}

O Instituto Politécnico da UFRJ em Cabo Frio se instituiu em 2008, a partir da iniciativa do Núcleo Interdisciplinar UFRJ Mar ${ }^{5}$, tendo a politecnia e o trabalho como princípios educativos e principais referências para a constituição de um novo modelo de educação profissional e tecnológica. Isso não quer dizer, no entanto, que em todo o período de existência de ambas as instituições de ensino esses princípios puderam ser seguidos a risca, já que muitos são os entraves para a formulação e construção de um modelo contra-hegemônico de educação.

Apesar de se ter ciência de que as condições estruturais impostas pelo modo de produção hegemônico são obstáculos cotidianos para o desenvolvimento de uma prática pedagógica inspirada na politecnia, à proposta do IPUFRJ sempre teve em seu horizonte esse princípio. A educação integral dos alunos - numa perspectiva emancipatória e contra-hegemônica -, ainda que algo pouco palpável em alguns momentos, sempre foi o que orientou a formulação do Instituto Politécnico. Mesmo que essas condições se apresentem como elementos inviabilizadores, a politecnia nunca deixou de ser um parâmetro a ser observado em todos os movimentos feitos dentro da escola.

Isso se dá principalmente pela crença de que o modelo de educação profissional vigente, marcado pela divisão, é insuficiente não só para a educação integral dos trabalhadores, mas também para as próprias condições atuais do capitalismo no país. Há, portanto, um vácuo a se preencher no que se refere à

\footnotetext{
${ }^{5}$ O Núcleo Interdisciplinar UFRJ-Mar foi responsável pela criação do Instituto Politécnico da UFRJ em Cabo Frio. Além disso, manteve, em parceria com a Prefeitura de Macaé - município do norte fluminense -, entre 2006 e 2009, a Escola Municipal de Pescadores, que foi regida pelos mesmos princípios do IPUFRJ, porém com algumas diferenças no que se refere a metodologia de ensino e funcionamento da escola.
}

TrabalhoNecessário - www.uff.br/trabalhonecessario; Ano 11, № 16/2013. 


\title{
Trabalhonecessário
}

Issn: 1808 - 799X

ano $11, \mathrm{n}=16-2013$

educação profissional no Brasil, e a proposta de um modelo calcado na politecnia pode ser uma alternativa. É evidente que a construção desse modelo não pode ser desarticulada de um projeto de construção de uma sociedade menos excludente.

Alguns documentos, redigidos quando da inauguração da escola, deixam clara a opção por um modelo de educação que não alijasse o trabalhador de uma formação intelectual necessária à compreensão do processo produtivo. No trecho que se segue, essas ideias estão evidentes:

\begin{abstract}
Numa tentativa de pensar um espaço educativo que possua como princípio o trabalho; tendo em vista a sua função não como reprodutor de uma ordem social, mas como espaço de socialização de conteúdos acumulados pela sociedade visando à transformação desta mesma sociedade, não pactuando, portanto, com a ruptura trabalho manual e intelectual; produção e educação, apresentamos a seguir o projeto do Instituto Politécnico da UFRJ (COSTA; MATSUNAGA; AMORIM, 2008, p. 3).
\end{abstract}

Esse extrato do projeto do Programa do Instituto Politécnico da UFRJ, evidencia a forte influência dos escritos de Karl Marx na proposta pedagógica ali apresentada. Assim como os autores do projeto, Marx acreditava que "o ensino permitirá aos jovens acompanhar o sistema total de produção" e que "eliminará dos jovens aquele caráter unilateral imposto a todo indivíduo pela divisão do trabalho" (MARX; ENGELS, 2005).

Em outro documento fundador do IPUFRJ e das demais iniciativas de cunho pedagógico do Núcleo Interdisciplinar UFRJ Mar, redigido pela professora Maria Helena Silveira, aparece à preocupação com os profissionais que viriam a ser formados pela escola:

Há anos caímos na superespecialização no ensino, tópicos ou unidades de disciplinas vieram a se constituir em "novas disciplinas", microfragmentando informações, em prejuízo da constituição conceitual e da formação profissional de intelectuais que possam vir a ser dirigentes [grifo nosso] (SILVEIRA, 2006, p.4).

TrabalhoNecessário - www.uff.br/trabalhonecessario; Ano 11, № 16/2013. 


\section{Trabalhonecessário}

Issn: 1808 - 799X

ano 11, no $16-2013$

O uso do termo dirigente faz referência direta à concepção gramsciana de dirigente inerente aos intelectuais orgânicos - no caso específico de uma escola profissional como o IPUFRJ, aos intelectuais da classe trabalhadora. Essa perspectiva pressupõe o horizonte emancipatório dessa mesma classe social, perspectiva essa que rege a concepção de formação humana do Instituto.

O trecho supracitado traz ainda uma preocupação adicional com a questão da fragmentação do conhecimento. Essa questão foi enfrentada na escola com uma abordagem metodológica diferenciada, que previa, primeiramente, o alargamento das áreas de conhecimento em relação às disciplinas tradicionalmente abordadas nas escolas de tradição burguesa. As disciplinas são organizadas em campos de conhecimentos e, dessa forma, têm-se Relações Sociais (História, Geografia Política, Sociologia, Filosofia e Antropologia); Prática de Comunicação Social e Arte (Português, Literatura, Artes, Línguas estrangeiras e Comunicação); Construção Naval e outras Tecnologias (Matemática, Física e Geometria); Ciências do Ambiente (Biologia, Geografia Física e Química) e Práticas Desportivas Aquáticas e Terrestres (Educação Física, porém de forma mais abrangente do que convencionalmente se desenvolve nas escolas, de um modo geral).

Destacamos, também, o papel do trabalho na formação dos alunos e como isso se materializava no cotidiano escolar. Toda parte pedagógica acontece a partir do desenvolvimento de algum projeto. Os projetos tinham como finalidade a produção de algo socialmente útil. Neste processo, de acordo com as demandas do que se pretende construir, os estudantes desenvolviam atividades práticas e teóricas, tendo em vista a apropriação de conhecimentos inerentes ao objeto em construção. Tal processo poderá ser melhor compreendido com a análise - 


\section{Trabalhonecessário}

Issn: 1808 - 799X

ano $11, \mathrm{n}=16-2013$

contida no próximo ponto deste trabalho - de um dos projetos pedagógicos desenvolvidos no Instituto Politécnico.

Este movimento da escola nos remete ao pressuposto básico da concepção marxista que fora apontado no primeiro ponto deste artigo - a relação da educação com o trabalho produtivo e a associação entre trabalho manual e intelectual. Podemos perceber a relevância deste movimento no processo formativo ao ler o que Makarenko escreve sobre o tema:

\footnotetext{
Ocorre que o processo de ensino na escola e a produção determinam solidamente a personalidade do indivíduo, porque eliminam a divisão que existe entre o trabalho físico e o mental, formando conjuntamente pessoas altamente qualificadas. (...) As condições de produção, de uma produção séria, eram as premissas que facilitavam o trabalho pedagógico. Agora lutarei para que em nossa escola soviética haja produção, principalmente porque o trabalho das crianças abre muitos caminhos para a educação. (MAKARENKO, 2002, p. 391-392)
}

Como podemos observar, o trabalho aparece como uma condição necessária no processo formativo na concepção marxista. No IPUFRJ, essa também é uma preocupação constante, contudo, nem sempre a condição de sua realização ocorre conforme fora esboçado teoricamente por Marx e nas experiências da pedagogia soviética, pois no IPUFRJ o trabalho não está articulado a um complexo produtivo mais amplo. A situação do trabalho é real, visto que produzem objetos socialmente úteis, porém o trabalho, como princípio pedagógico se materializa na atividade criadora e não na relação de produção. $O$ que se produz não é vendido ou comercializado, tem um fim apenas pedagógico. Este movimento mostra-se bastante fecundo, pois o tempo tem revelado que a apropriação dos conceitos tem acontecido de forma mais satisfatória do que nos modelos convencionais, cuja ênfase recai na abstração pura e idealista.

Finalmente, é importante dizer que outras opções metodológicas foram estabelecidas como marco, dando um caráter peculiar à escola em sua estrutura 


\section{Trabalhonecessário}

Issn: 1808 - 799X

ano $11, \mathrm{n}=16-2013$

e funcionamento. O IPUFRJ desenvolve sua metodologia de trabalho em tempo integral prevendo atividades motoras e intelectuais de forma articulada, compondo assim um currículo integrado.

\section{A prática pedagógica do IPUFRJ: o trabalho como princípio educativo, a partir da pedagogia de projetos}

Talvez a maior contribuição que o Instituto Politécnico da UFRJ em Cabo Frio venha dando para a consolidação da formação integrada esteja na questão da metodologia de ensino. A escola, desde seus primórdios, vem conduzindo a sua prática pedagógica a partir da Pedagogia de Projetos (ou Método de Projetos). Neste ponto do artigo, tentaremos analisar como essa metodologia pode ser útil na abordagem do trabalho como princípio educativo e na integração da formação geral e profissional, bem como na interação dos diversos campos do conhecimento.

Essa escolha metodológica está justificada em um dos documentos fundadores da escola, da seguinte forma:

[o projeto pedagógico da escola] é estruturado com base em projetos de caráter interdisciplinar, que são uma forma de romper com a prisão das grades curriculares, das disciplinas estreitas - que não conseguem dar conta da complexidade do mundo do trabalho, nem da complexidade dos currículos tradicionais. Não é um desafio pequeno. (AMORIM; SILVEIRA, 2006, p. 4).

A Pedagogia de Projetos, no entanto, está historicamente ligada ao pensamento pedagógico de John Dewey, que na primeira metade do século XX, passa a contestar os métodos de aprendizagem propostos pelo que ele veio a chamar de "escola tradicional". A base da crítica de Dewey estava na passividade atribuída ao educando por parte das metodologias de ensino tradicional. Ele propunha, então, uma nova concepção de educação, na qual o conhecimento se 


\section{Trabalhonecessário}

Issn: 1808 - 799X

ano $11, \mathrm{n}=16-2013$

desenvolvesse a partir de uma relação entre a sociedade e o individuo. Essa proposição seria a base da concepção de construtivismo, vinda da tradição filosófica pragmática estadunidense, que valorizava a experiência e a reconstrução individual da experiência como ponto de partida para a construção de conhecimento e do processo de aprendizagem.

A partir dessa base filosófica, surgiram os primeiros trabalhos que propunham a aprendizagem a partir de projetos. O primeiro deles foi proposto por William Kilpatrick, em $1918^{6}$, e recebeu o nome de "Método de Projetos". Baseado no pragmatismo deweyano, Kilpatrick propôs uma alternativa didática em que se parte das necessidades, interesses e problemáticas do educando, pretendendo gerar um processo de aprendizagem significativo. Além disso, o aspecto interacionista é valorizado, tendo o aluno um papel determinante no seu processo de aprendizagem, já que o mesmo se dá a partir da interação dele com o meio.

Essas ideias tiveram repercussão no Brasil, a partir de educadores como Anísio Teixeira e Lourenço Filho, na década de 1930 e o estabelecimento da chamada Escola Nova. A partir desse movimento, o pensamento de Dewey e Kilpatrick passa a ser referência para a construção de um referencial pedagógico alternativo no país.

Mas o que esse tipo de pensamento de base pragmática e que surgiu para atender às novas necessidades de aprendizagem impostas pelo modo de produção capitalista, no início do século passado, pode contribuir para a construção de uma metodologia de ensino que se pretende contra-hegemônica? A resposta a essa questão pode estar na análise da Pedagogia de Projetos, a partir da perspectiva histórico-cultural de Lev Vygotsky.

\footnotetext{
${ }^{6} \mathrm{O}$ texto original está reproduzido na internet como KILPATRICK, William. The Project Method: The Use of the Purposeful Act in the Educative Process. Columbia University: New York, 1918. (disponível em: http://people.umass.edu/ rwellman/Philosophy/Kilpatrick.pdf. Acessado em 31 de maio de 2012).
}

TrabalhoNecessário - www.uff.br/trabalhonecessario; Ano 11, № 16/2013. 


\section{Trabalhonecessário}

Issn: 1808 - 799X

ano $11, \mathrm{n}=16-2013$

Mesmo estando em campos teóricos diametralmente opostos, os pensamentos de Dewey e Vygotsky encontram coincidências no que se refere à perspectiva interacionista entre o indivíduo e a sociedade na construção de conhecimento. $\mathrm{O}$ que difere esses dois pensadores está basicamente na percepção dialética que o pensador soviético propõe, visando a proposição de uma psicopedagogia histórico-cultural.

A partir desta perspectiva, pode-se dizer que a Pedagogia de Projetos, associada a elementos das propostas ligadas à teoria histórico-cultural da atividade - segundo preceitos formulados por autores como Leontiev, Davydov e Vygotsky -, traz uma nova perspectiva para entendermos o processo de ensinoaprendizagem, isto porque apresenta uma ressignificação do espaço escolar, transformando-o em um espaço vivo de interações. Possibilita ao educando fazer parte do processo de construção de conhecimento, ao voltar-se para uma ação concreta, de resolução de problemas da sua realidade e na construção de uma prática social.

Além disso, essa perspectiva traz elementos importantes para a reflexão sobre o trabalho como princípio educativo já que, a partir da Pedagogia de Projetos, pode-se pensar em perspectivas de aprendizagem pelo trabalho. Por isso, a análise da prática pedagógica do Instituto Politécnico da Universidade Federal do Rio de Janeiro em Cabo Frio torna-se relevante, como evidenciam Porto, Maciel e Silva (2011):

\footnotetext{
A pedagogia de projetos auxilia na proposta pedagógica do Instituto na medida em que se constitui o caminho pelo qual o aluno vai percorrer para construção de um produto socialmente útil. Na prática, [...] os alunos são apresentados à proposta do projeto, no qual é esclarecido o tema e a relevância do mesmo para a sociedade e, também, são estabelecidos os objetos a serem construídos por eles. O percurso da construção do objeto é traçado pelo aluno, a partir de suas demandas, que surgem durante o processo de elaboração desse produto. Ou seja, a partir de algumas problematizações sobre o tema do projeto proposto pelos professores, os educandos percebem a necessidade de se
}

TrabalhoNecessário - www.uff.br/trabalhonecessario; Ano 11, № 16/2013. 


\title{
Trabalhonecessário
}

Issn: 1808 - 799X

ano $11, \mathrm{n}=16-2013$

\begin{abstract}
apropriarem de novos conceitos que servirão de base para a conclusão do projeto. Portanto, o aluno aprende no processo de produzir, de levantar dúvidas, de pesquisar e de criar relações, que incentivam novas buscas, descobertas, compreensões e reconstruções de conhecimento. Nogueira (2006), em seu livro Pedagogia dos Projetos: etapas, papéis e atores, discute a questão da formação integral dos alunos e propõe o trabalho com projetos como uma das possibilidades para este fim. Para este autor (2006, p.88), o referido projeto, livrando-se de definições reducionistas, é "[...] a princípio, uma irrealidade que vai se tornando real, conforme começa ganhar corpo a partir da realização de ações e, consequentemente, as articulações destas." (PORTO; MACIEL; SILVA, 2011, p. 4-5).
\end{abstract}

O outro aspecto a se considerar é o caráter integrador das práticas pedagógicas referenciadas na Pedagogia de Projetos. Essa metodologia permite uma maior desfragmentação do conhecimento, além de facilitar a integração entre as questões referentes à formação geral e a educação profissional.

\section{Pedagogia de projetos e o trabalho como princípio educativo: mediação pedagógica no projeto de construção da prancha de agave}

O Instituto Politécnico da UFRJ oferece formação integrada em três especialidades técnicas: Produção em Áudio e Vídeo; Análises Químicas e Cultura Marítima.

O curso técnico em Cultura Marítima proporciona, com base nos pressupostos teóricos e metodológicos que fundamentam a pedagogia do Instituto, formação integrada para os alunos desenvolverem a capacidade de atuação crítica e formulação de proposta de contribuição no campo da pesca e aquicultura, da construção naval e do mergulho. A relevância da formação de quadros profissionais nestes campos pode ser percebida ao lermos um trecho do Projeto Político Pedagógico:

[...] é especialmente relevante para a região em razão da importância do complexo de atividades que envolvem a construção, a manutenção e o reparo de pequenas embarcações para a Região dos Lagos, ao longo das últimas décadas: além dos benefícios verificados no domínio de sua própria atuação, a persistência dos pequenos empreendedores do setor contribuiu também de modo decisivo para a manutenção da

TrabalhoNecessário - www.uff.br/trabalhonecessario; Ano 11, № 16/2013. 


\section{Trabalhonecessário}

Issn: 1808 - 799X

ano $11, \mathrm{n}=16-2013$

atividade pesqueira e para o fortalecimento da identidade marítima que orienta o potencial turístico de toda a região (INSTITUTO, 2011, p.1).

O primeiro ano do ensino médio integrado tem como objetivo primário preparar o aluno para entender todo o processo produtivo e não só a sua função específica nesse processo. Daí a necessidade de fornecer a esse estudante um ensino integral, que dê conta das demandas gerais de formação e não só das tarefas específicas de sua futura posição no processo produtivo. Por conta disso, foram delimitados dois conceitos básicos a serem trabalhados com os alunos do primeiro ano do Ensino Médio: Ciência e Trabalho.

Estes conceitos são trabalhados de maneira dialética, para que os alunos, ao longo do ano letivo, possam não somente escolher entre as carreiras específicas oferecidas pelo Instituto, como principalmente serem capazes de compreender como as transformações científicas têm efeitos diretos nas relações produtivas. Portanto, será a partir do segundo ano do ensino médio integrado que os alunos optarão pelas áreas técnicas de formação.

Para este trabalho, será analisado o projeto pedagógico realizado no ano de $2011 \mathrm{com}$ a turma do segundo ano do curso técnico integrado em Cultura Marítima, com o objetivo de compreender a Pedagogia de Projetos, à luz das experiências metodológicas do IPUFRJ. Portanto, o tomaremos como ponto de partida para compreender um possível diálogo na construção da formação integrada entre o ensino médio e o ensino profissional, e mais profundamente refletir sobre a concepção de formação humana a partir da questão do trabalho como princípio educativo.

Tomamos o materialismo histórico e dialético como referencial de análise dos documentos que orientam as práticas pedagógicas do Instituto. Além disso, para esta pesquisa buscamos construir uma reflexão crítica sobre nossa própria prática docente, procurando criar condições de uma nova ação pedagógica. 


\section{Trabalhonecessário}

Issn: 1808 - 799X

ano $11, \mathrm{n}=16-2013$

Assim trazemos, para este trabalho, uma atitude investigativa que tem nos tornado, também, pesquisadores sobre o que exercemos e sujeitos do que investigamos.

Para compreender como são construídas as representações do trabalho enquanto principio educativo - a partir da referência de politecnia -, o ensino integrado e a formação humana na prática pedagógica, foi delimitado o contexto empírico que envolve a elaboração dos projetos pedagógicos, os conteúdos previstos e as atividades planejadas enquanto constituintes de significados que possibilitam a análise da Pedagogia de Projeto dentro da proposta do ensino integrado.

No inicio de 2011, a equipe interdisciplinar de professores do curso de Cultura Marítima elaborou o projeto pedagógico "Construção de prancha com material alternativo não poluente" para ser desenvolvido durante o primeiro semestre pelos alunos da segunda série. O projeto consistiu na construção de uma prancha de surfe utilizando, como matéria-prima, a madeira de agave, planta originária do México e disseminada na região Nordeste e Sudeste do Brasil, com presença marcante em nosso ecossistema de restinga.

O projeto foi elaborado com o objetivo de proporcionar, a partir do eixo temático da construção naval, a apropriação de conhecimentos técnicos e práticos do trabalho com a madeira, a fim de aplicá-los na construção de embarcações e outros produtos. Tomando como ponto de partida a compreensão dos processos tecnológicos inerentes à área profissional, o projeto pedagógico se mostrou amplo o suficiente para favorecer a inserção entre as diversas áreas do conhecimento, ao permitir uma abordagem interdisciplinar, assim como assinala Ramos:

TrabalhoNecessário - www.uff.br/trabalhonecessario; Ano 11, № 16/2013. 


\title{
Trabalhonecessário
}

Issn: 1808 - 799X

ano $11, \mathrm{n}=16-2013$

\begin{abstract}
Isto significa elaborar questões sobre os fenômenos, fatos, situações e processos identificados como relevantes, com o intuito de desvelar sua essência - características, determinantes, fundamentos - que não se manifestam de imediato à nossa percepção e/ou experiência. Responder às questões elaboradas produzirá a necessidade de se recorrer a teorias e conceitos já formulados sobre o(s) objeto(s) estudado(s) e esses se constituirão em conteúdos de ensino. (RAMOS, 2007 p.20)
\end{abstract}

A problematização dos fenômenos inerentes à compreensão da realidade concreta, a partir da mediação do trabalho como princípio educativo, possibilita a percepção das múltiplas dimensões do processo de produção. Cabe analisar para este trabalho a perspectiva relacional na qual estão articulados os objetos estudados, buscando perceber como se constrói a totalidade curricular.

Ao analisa-lo - o projeto de construção da prancha de agave - pela dimensão do campo de conhecimento da Construção Naval e suas tecnologias, foram trabalhados conhecimentos de desenho, de relevos figurativos, ornatos, buscando aguçar a criatividade e o raciocínio sobre a elaboração do objeto final. Durante as atividades desenvolvidas, os alunos adquiriram habilidades com o manuseio de ferramentas, por meio das técnicas de escultura, com entalhe em madeira do agave, vinculando com os conceitos básicos da física relacionados à flutuação, equilíbrio e resistência de materiais.

A partir da perspectiva da área de conhecimento das Ciências do Ambiente, foi problematizada a presença da espécie exótica do Agave no ecossistema costeiro de restinga, possibilitando explorar os fenômenos associados à formação dos ecossistemas da região, trabalhando com conceitos e parâmetros ambientais das áreas da biologia, oceanografia e geologia. O projeto proporcionou, ainda, a familiarização dos alunos com as técnicas e conhecimentos necessários para a elaboração de um plano de manejo, tendo como perspectiva a superação dos conflitos ambientais presentes em área de preservação.

TrabalhoNecessário - www.uff.br/trabalhonecessario; Ano 11, № 16/2013. 


\section{Trabalhonecessário}

Issn: 1808 - 799X

ano $11, \mathrm{n}=16-2013$

A área de conhecimento de Relações Sociais buscou, a partir do processo histórico de ocupação das restingas da região, a compreensão da realidade local enquanto construção histórica e material, fomentando a reflexão acerca da relação sociedade e natureza e uma análise crítica sobre o desenvolvimento sustentável e a formulação de políticas públicas socioambientais. Além disso, foram abordadas questões relativas às relações de trabalho na indústria naval, mais especificamente nas indústrias e manufaturas que produzem materiais para a prática do surfe.

O contexto do surfe também provocou a discursão em torno dos aspectos sociais, econômicos e culturais historicamente construídas, explicitando os conceitos de trabalho, memória e identidade.

O projeto pedagógico da construção da prancha previu a elaboração de um manual com as etapas da produção, utilizando-se de recursos audiovisuais, fotografia e formas textuais. A área de conhecimento Prática de Comunicação Social e Artes contribui com a confecção deste material, ao dar subsídio para os alunos desenvolverem a capacidade quanto ao domínio dos recursos de comunicação social e de diferentes línguas (português e inglês) e linguagens artísticas como instrumentos de produção científica e cultural.

Um dos eixos norteadores do curso técnico em Cultura Marítima é a adaptação do aluno ao ambiente aquático, através de atividades desenvolvidas pela equipe do campo de conhecimento de Práticas Desportivas Aquáticas e Terrestres. Essa abordagem é baseada na ideia de que a autonomia do trabalhador no mar é fundamental para o desenvolvimento de qualquer trabalho que envolva a pesca, a aquicultura, o mergulho e a construção naval.

Para o projeto analisado, foi delimitado o desenvolvimento de atividades que estimulassem, a partir da prática do surfe, a adaptação ao meio aquático com natação marítima sem ondas e com ondas, proporcionando aos alunos uma

TrabalhoNecessário - www.uff.br/trabalhonecessario; Ano 11, № 16/2013. 


\section{Trabalhonecessário}

Issn: 1808 - 799X

ano $11, \mathrm{n}=16-2013$

progressiva consciência quanto aos limites e possibilidades de seu corpo. Além disso, as práticas de natação e do surfe mostraram-se eficazes no condicionamento físico dos alunos para a realização dos trabalhos.

Diante do desafio de estruturar o ensino integrado, que tenha a politecnia como referência, o Instituto Politécnico da UFRJ buscou na Pedagogia de Projetos uma alternativa metodológica que possibilitasse na prática pedagógica a formação integrada entre o ensino médio e o técnico. O projeto "Construção de prancha com material alternativo não poluente" mostrou a possibilidade de desenvolver uma formação humana com base na integração de todas as dimensões da vida, a partir do processo formativo, ao proporcionar uma formação omnilateral diante da indissociabilidade entre a educação profissional e a educação básica, entre atividade manual e intelectual.

Ao tomar o trabalho enquanto principio educativo para a formação, os alunos se apropriam da sua realidade e se tornam capazes de transforma-la. Portanto, o trabalho é a primeira mediação entre o homem e a produção material e imaterial da vida. Assim, o conceito de mediação pode aprofundar o sentido da relação entre trabalho e educação ao permitir uma visão historicizada do objeto estudado em suas determinações universais, assim como situa-lo dentro de sua particularidade histórica. De acordo com Ciavatta,

\footnotetext{
A mediação não é um instrumento analítico de medição quantitativa do comportamento de um fenômeno, nem a busca da relação de causa e efeito, mas sim, é a especificidade histórica do fenômeno. A mediação situa-se no campo dos objetos problematizados nas suas múltiplas relações no tempo e no espaço, sob a ação de sujeitos sociais (CIAVATTA, 2001, p. 132).
}

Para tanto, a Pedagogia de Projetos mostrou-se eficaz na integração de conhecimentos gerais e específicos enquanto instrumento para promover maior iniciativa de professores e alunos no processo formativo, combatendo a visão 


\section{Trabalhonecessário}

Issn: 1808 - 799X

ano 11, no $16-2013$

compartimentada e hierárquica na qual foram posto historicamente as formas de conhecimento.

Com o intuito de facilitar a compreensão de como se dá a integração dos conhecimentos, bem como a mediação entre as múltiplas dimensões da totalidade que envolve o trabalho educativo proposto pelo projeto, compusemos o seguinte esquema explicativo:

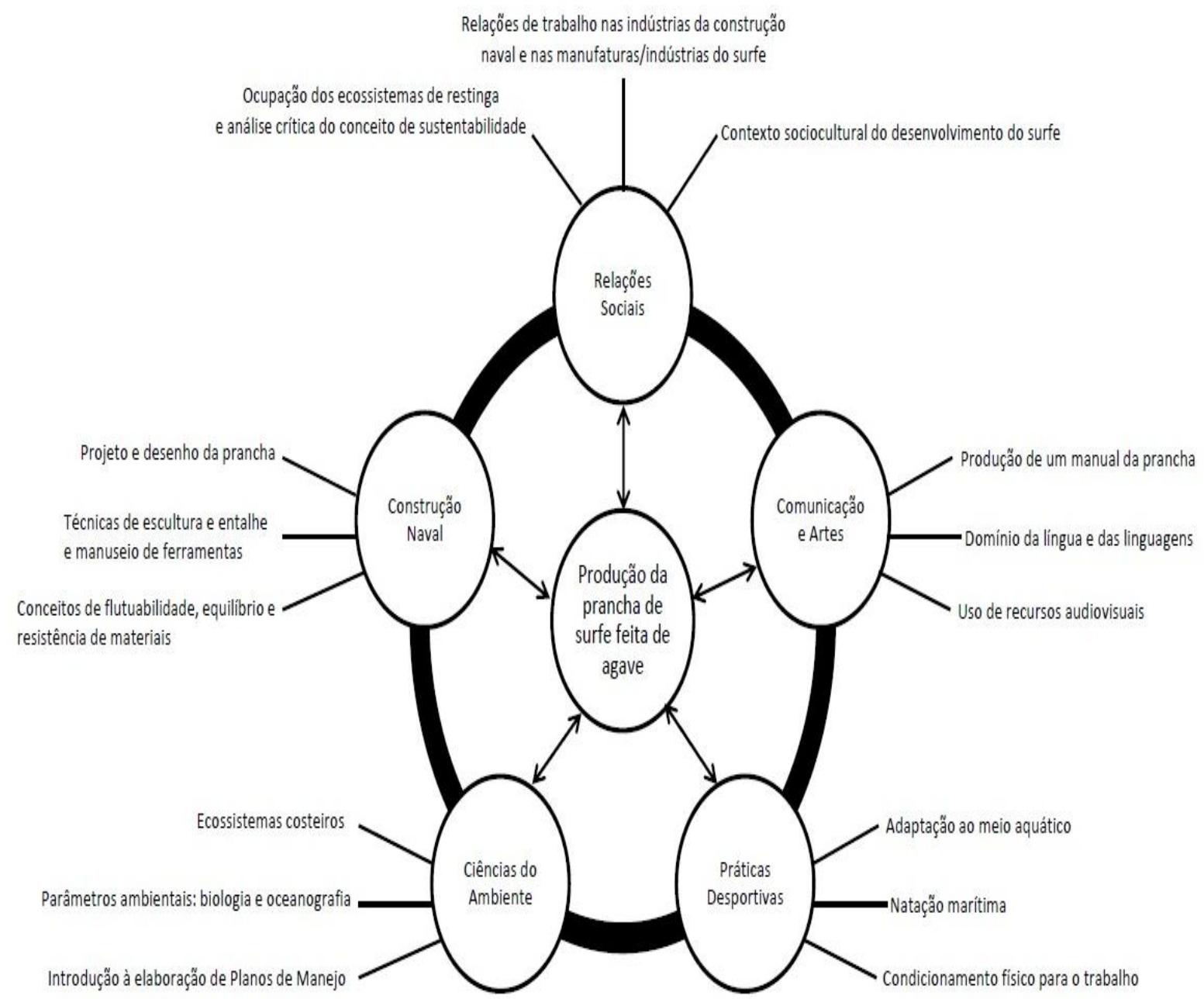

TrabalhoNecessário - www.uff.br/trabalhonecessario; Ano 11, № 16/2013. 


\section{Trabalhonecessário}

Issn: 1808 - 799X

ano 11, no $16-2013$

\section{Considerações finais}

Este trabalho buscou explicitar a concepção de formação humana do Instituto Politécnico da UFRJ em Cabo Frio (IPUFRJ). A partir da análise dos "documentos fundadores", pode-se perceber forte influência de pensadores marxistas na construção da concepção de formação humana da escola. No entanto, não houve a pretensão de fazer qualquer tipo de afirmação que leve a entender que a experiência do IPUFRJ foi, de fato, um exemplo de formação humana numa perspectiva marxista, nem muito menos afirmar que se desenvolve uma educação marxista. $O$ que se buscou foi trazer para o debate, a necessidade de se pensar uma proposta de formação humana que seja resultante de ações intencionais dotadas de conteúdo político e filosófico capaz de ser um referencial importante para a promoção de uma educação integral, plena, que possibilite aos sujeitos atuarem de forma crítica e ativa na sociedade, tendo em vista a superação dos inúmeros problemas que deforma a natureza humana.

Neste sentido, podemos afirmar que abordar a perspectiva marxista de formação humana, a partir da análise de uma experiência concreta, de fato foi intencional, pois se acredita neste caminho como uma condição necessária para se pensar um processo educativo, que tenha em vista a transformação da sociedade.

Os teóricos da pedagogia soviética, assim como a escola unitária de Gramsci se apresentam como suporte teórico e metodológico importante para a construção de um modelo educativo, cujo objetivo seja a formação para a transformação, pois, ao se respaldarem no materialismo histórico e dialético para formular novos preceitos teóricos sobre a educação, ou enquanto suporte para análise de suas experiências nos deixam contribuições relevantes, mas, que 


\section{Trabalhonecessário}

Issn: 1808 - 799X

ano 11, no $16-2013$

precisam ser reformuladas e revistas de acordos com as condições reais que vivemos.

Pode-se dizer que a concepção de formação humana do Instituto Politécnico da UFRJ está estabelecida a partir: (1) do trabalho como princípio educativo - posto em prática na escola a partir da Pedagogia de Projetos -; (2) da integração entre a formação geral e técnica dos alunos - bem como a interação entre os diferentes campos do conhecimento. Por isso, o IPUFRJ nos possibilita pensar um caminho alternativo ao que é hegemônico, tendo como horizonte uma formação humana capaz de intervir de forma crítica na sociedade. Analisar as condições pelas quais se constituiu o trabalho nos permite perceber que para se desenvolver o processo educativo por este viés faz-se necessário questionarmos para qual sociedade se quer formar e, indagarmos, também o que se tem legitimado nas práticas educativas desenvolvidas no cotidiano das escolas. Refletir sobre outros caminhos a partir de experiências concretas, ainda que de forma isolada, contribui para que se vislumbre novas alternativas.

Dentre as contribuições do IPUFRJ para a consolidação da formação integrada de trabalhadores, destaca-se a questão metodológica. A utilização da Pedagogia de Projetos para a abordagem da educação pelo trabalho, além de ser bastante original, tem-se mostrado uma inovadora experiência. Acreditamos que essa metodologia seja adequada às escolas de formação profissional, em especial às que adotam a modalidade integrada ao ensino médio, já que a mesma proporciona grande potencialidade no caráter integrador do trabalho e na interação entre as diversas dimensões que o compõe em sua totalidade.

TrabalhoNecessário - www.uff.br/trabalhonecessario; Ano 11, № 16/2013. 


\section{Trabalhonecessário}

Issn: 1808 - 799X

ano 11, no $16-2013$

\section{Referências Bibliográficas}

AMORIM, Fernando; SILVEIRA, Maria Helena. Uma Escola, Um Sonho, Uma Realidade. Rio de Janeiro: Núcleo Interdisciplinar UFRJ Mar, 2006. (disponível em: http://pt.scribd.com/doc/24373540/Uma-Escola-Um-Sonho )

BERNSTEIN, B. A Estruturação do Discurso Pedagógico: classe, código e controle. Petrópolis: Vozes, 1996.

CIAVATTA, M. Trabalho como Princípio Educativo. Dicionário de Educação Profissional em Saúde. Rio de Janeiro: Fundação FioCruz, 2008.

CIAVATTA, Maria. O conhecimento histórico e o problema teórico-metodológico das mediações. In: CIAVATTA, M; FRIGOTTO, Gaudêncio (org.). Teoria e Educação no Labirinto do Capital. Petrópolis: Vozes, 2001.

CIAVATTA, M.; RAMOS, M. Ensino Médio Integrado. In: CALDART, Roseli S. et al. Dicionário Educação do Campo. Rio de Janeiro/São Paulo: EPSJV/Expressão Popular, 2012.

CIAVATTA, M. Ensino Integrado, Politecnia e Educação Omnilateral: Por que lutamos? In: VII Seminário sobre Trabalho e Educação: uma década sobre estudos de trabalho e educação na Amazônia. Universidade Federal do Pará. 2011.

CONSELHO Nacional de Educação. Câmara de Educação Básica. Diretrizes Curriculares Nacionais para a Educação Profissional Técnica de Nível Médio. Brasília: CNE/CEB, 2012.

COSTA, Luiz Henrique; MATSUNAGA, Priscila; AMORIM, Fernando. Da Proposta Politécnica e o Programa de Institutos Politécnicos. Rio de Janeiro: Núcleo Interdisciplinar UFRJ Mar, 2008. Disponível em: http://pt.scribd.com/doc/24373532/inst-politecnicos (acesso em 10/11/2012) 


\section{Trabalhonecessário}

Issn: 1808 - 799X

ano 11, no $16-2013$

FRIGOTTO, Gaudêncio. O enfoque da dialética materialista histórica na pesquisa educacional. In: FAZENDA, Ivani (Org). Metodologia da pesquisa educacional. São Paulo: Cortez, 2004, p. 59-68

FRIGOTTO, G. Os "homens de negócio" e a política educacional do MEC. In: Revista Histedbr Online. n. 4. Unicamp: Campinas. 2001.

GRAMSCI, Antonio. Cadernos do cárcere: Volume 2.Os intelectuais. O princípio educativo. Jornalismo. 6ª ed. Rio de Janeiro: Civilização Brasileira, 2014.

LUEDEMANN, Cecília S.. Anton Makarenko: vida e obra - a pedagogia na revolução. São Paulo: expressão popular, 2002;

MANACORDA, Mario Alighiero. O princípio educativo em Gramsci: americanismo e conformismo. $2^{\text {a }}$ Ed. Campinas, SP: Alínea editora, 2008.

Mario Alighiero. Marx e a pedagogia moderna. $2^{\mathrm{a}}$ Ed. Campinas, SP: Alínea editora, 2010a.

Mario Alighiero. História da educação: da antiguidade aos nossos dias. 13ª Ed. São Paulo: Cortez, 2010b.

MARX, Karl. Textos sobre Educação e ensino. 4 ed. São Paulo. Centauro, 2004.

PISTRAK, M. Fundamentos da escola do trabalho. São Paulo: Expressão Popular, 2000;

PORTO, C.; MACIEL, C.; SILVA, M. G. Instituto Politécnico da Universidade Federal do Rio de Janeiro: Uma Proposta de Construção de Educação pelo e para o Trabalho. In: Anais do V Encontro Brasileiro de Educação e Marxismo. Florianópolis: UFSC, 2011.

RAMOS, Marise. Concepção do Ensino Médio Integrado. São Paulo: IIEP, 2007. Disponível em: http://www.iiep.org.br/curriculo integrado.pdf (acesso em 10/11/2012)

SAVIANI, D. Pedagogia Histórico-crítica: primeiras aproximações - 10. Ed. Campinas, SP: Autores Associados, 2008. 


\section{Trabalhonecessário}

Issn: 1808 - 799X

ano 11, no $16-2013$

O choque teórico da politecnia. Trabalho, Educação e Saúde, - v. 1, n. 1 (2002). Rio de Janeiro : Fundação Oswaldo Cruz, Escola Politécnica de Saúde Joaquim Venâncio, 2002.

SILVEIRA, Maria Helena. Preocupações Psicopedagógicas: Grupos de Trabalho Interdisciplinar. Rio de Janeiro: Núcleo Interdisciplinar UFRJ Mar, 2006. Disponível em: http://pt.scribd.com/doc/24373441/preocupacoespsicopedagogicas

Data de recebimento: 17/02/2013

Data de aprovação: 25/03/2013 